\title{
REFLEXIONES SOBRE EL SUBPROGRAMA DE EDUCACIÓN PARA LA VIDA Y EL TRABAJO
}

Rosario Camargo Espriú Regina Jiménez-Ottalengo

\section{RESUMEN}

El propósito de este ensayo es analizar el Subprograma de Educación para la Vida y el Trabajo presentado en el Programa de Educación 2001-2006, en septiembre de 2001, por la Secretaría de Educación Pública. El Subprograma está destinado a atender a la población mexicana que ha truncado su educación formal. A partir de esta revisión se intenta mostrar que el Subprograma presenta importantes limitaciones al hacer demasiado énfasis en los aspectos relacionados con la capacitación laboral, dejando de lado las cuestiones vinculadas con la convivencia y los valores sociales.

Con el fin de identificar las orientaciones fundamentales de dicho Subprograma, se analizó tanto en su contexto implícito, como en su contexto explícito. El implícito, hace referencia a los mensajes que tanto el Presidente de la República, como el Secretario de Educación presentan en la primera parte del Programa de Educación 2001-2006, así como la Introducción del mismo. El contexto explícito remite al contexto histórico en que se difundió, es decir, finales de 2001.

\section{INTRODUCCIÓN}

El Presidente Vicente Fox menciona en su mensaje tres valores ejes de la educación: equidad, calidad y vanguardia. Para él, este sistema educativo ayudará a cimentar las condiciones requeridas para un futuro con un pueblo preparado 
que desarrolle actividades productivas y propicie un alto nivel de vida a la población formada por ciudadanos responsables, solidarios, participantes y críticos.

Por su parte, el Secretario de Educación, Reyes S. Tamez Guerra, resalta la necesidad de que la educación prepare para el desarrollo sustentable, democrático, que fortalezca la soberanía nacional. Vislumbra la educación como un sistema amplio, equitativo, flexible, dinámico que, al mismo tiempo que esté articulado, se diversifique y logre la calidad de acuerdo a los cánones internacionales, procurando la participación social.

En la introducción al Programa, se hace referencia al papel desempeñado por la educación para lograr una nación democrática, en la que sus societarios alcancen una alta calidad de vida, orgullosos de sus raíces, se reconozca lo pluriétnico, lo multicultural, y se logre «un profundo sentido de unidad nacional". Se considera que la educación puede auxiliar para reducir las desigualdades sociales extremas y ofrecer a todos oportunidades de convivencia con respeto a la legalidad, ejercicio de los derechos humanos y equilibrio con el medio.

Los tres mensajes enfatizan en la preocupación por lograr que el proceso educativo sirva a la sociedad. Se puede interpretar que en el Programa subyace la inquietud por hacer de la sociedad mexicana una sociedad sana ${ }^{1}$, es decir, una sociedad en la que los societarios puedan convivir armónicamente, conscientes de sus similitudes y divergencias, respetuosos de su entorno natural y construido, y que participen en la construcción de un país con presente y futuro.

Para ir perfilando el camino que permita lograr esos objetivos, el Programa se divide en tres partes. La primera realiza un diagnóstico de la situación educativa y presenta la visión de lo deseable, los objetivos estratégicos y el planteamiento 43-52). 
de los mecanismos de evaluación y seguimiento. La segunda, aborda temas como la reforma de la gestión del sistema educativo, la federalización de la misma, el marco jurídico, los mecanismos de información y evaluación, y el control escolar. La tercera, expone los Subprogramas de educación básica (para la convivencia social), el Subprograma de educación media superior (para la maduración personal y social); el Subprograma de educación superior (profesionales que requieran la vida económica, social, política, cultural y científica del país) y el Subprograma de educación para la vida y el trabajo (dirigido a atender a los jóvenes y adultos que no terminan la educación secundaria y aumentar la competitividad de la economía mexicana en la sociedad del conocimiento).

En este ensayo nos centraremos en el análisis del Subprograma de Educación para la Vida y el Trabajo porque pretende rescatar a la amplia población que ha truncado sus estudios formales. Si bien es cierto que el concepto de educación para la vida y el trabajo se ha utilizado desde hace más de diez años por los organismos internacionales (OCDE, Banco Mundial, BID), el que aparezca ahora como parte de un programa sexenal (que pretende extrapolarse hasta el año 2025), llama al optimismo. Sin embargo, una vez analizado con cierto cuidado, se llega a la conclusión de que se quedó corto en sus aspiraciones, toda vez que sólo enfatiza los aspectos relacionados con la capacitación para el trabajo.

El Subprograma destaca la importancia de una educación que desemboque en un trabajo redituable, mejorando la condición económica de las personas. De igual forma, menciona lo trascendente de ampliar su horizonte cultural. Con todo, el énfasis parece centrarse en una educación para el trabajo, ya que constantemente se refiere a personas carentes de escolaridad, con honda preocupación por las personas analfabetas y de bajísima escolaridad, a las que se considera susceptibles de recibir el beneficio de una educación no formal, que les facilite los conocimientos indispensables para sumarse al grupo productivo de la sociedad. Hay en el Subrograma una seria 
preocupación por los desempleados y por quienes se dedican a la economía informal para que, mediante la educación, puedan capacitarse para trabajar en microempresas o autoempleo.

Cuando se habla de la necesidad de elevar en nivel educativo, se está refiriendo a la necesidad de gente preparada (al menos mínimamente) para incorporarse al aparato productivo, aunque también se menciona que el sistema educativo debe ofrecer oportunidades de aprendizaje a los ciudadanos de cualquier edad, cultivando "la diversidad de sus capacidades, vocaciones, estilos y necesidades para lo cual habrá que multiplicar la diversidad de la oferta" (2001:220).

El Subprograma enmarca su quehacer en la educación no formal, orientada a acrecentar el capital humano como factor para el bienestar y el desarrollo.

"Acrecentar el desarrollo bumano por medio de la educación para el bienestar y el desarrollo. Una educación no formal para la vida y el trabajo. Que desarrolle capacidades individuales y colectivas para preparar el cambio, que difunde y se apropie de la tecnología y permita la evolución de las prácticas laborales y evite la exclusión" (2001:220).

Más adelante señala: “(...) educación para la vida: orientación práctica que amplie el horizonte cultural y abra mejores oportunidades de trabajo" y "educación para el trabajo para grupos específicos: profesionales que se actualicen, trabajadores que se capaciten sobre las bases de competencias, miembros del sector rural, de la economía informal del autoempleo, microempresarios" (2001: 219,220).

Como puede observarse, el subprograma parece estar dominado por una visión economicista de la educación informal, y deja a un lado lo que debería ser una preocupación fundamental en una etapa de transición social y política: la formación de ciudadanos solidarios, participativos, críticos.

\footnotetext{
${ }^{2}$ En el texto se habla de ciudadanos lo que marca la preocupación meramente política del programa, se debe hablar de societarios; es decir, de todas las personas que vivan en el territorio sean o no ciudadanos, para que el programa realmente cubra las expectativas de convivencia.
} 
El Subprograma pretende cubrir a los 32.5 millones de jóvenes y adultos de 15 años y más que no terminaron la educación básica y que no son atendidos por el sistema escolarizado, con énfasis en "la capacitación laboral que cuide y potencie la iniciativa individual y aborde temas como: violencia, drogadicción, sexualidad y cultura" (2001:221), es decir, temas que se relacionan o incumben directamente con el problema de la convivencia armónica. A pesar de ello, creemos que un programa que se denomina de "educación para la vida y el trabajo" debería enfocarse con una perspectiva sociopedagógica que incorpore la noción de capital social", es decir, que aumente el cúmulo de virtudes y habilidades sociales relacionadas con la cohesión social, con expresiones culturales y con comportamientos sociales que conviertan una sociedad en una colectividad más cohesiva que trascienda a la suma de sus individuos.

Sostenemos que para detener la descomposición del tejido social, México requiere de una bien planeada educación para la vida, que incluya no sólo a esos 32 millones de personas que no pudieron terminar su educación básica, sino a todos los miembros de la sociedad. Aprovechar la estructura organizativa de CONEVYT (Consejo Nacional de Educación para la Vida y el Trabajo) constituida como un sistema tipo red, que pretende integrar programas de diferentes dependencias oficiales y de organismos no gubernamentales. Consideramos que el Subprograma debe reorientarse con una visión más ambiciosa, más hacia la formación de un capital social que aliente el compromiso, la confianza y la reciprocidad, así como el desarrollo de sistemas horizontales de interacción que promuevan la participación del tercer sector (el social) y que aliente, al mismo tiempo, el altruismo y la cohesión.

\footnotetext{
* Es un concepto de reciente uso que ha sido utilizado por las ciencias del desarrollo como clave para la competitividad del crecimiento sustentable ya que ayuda a la estabilidad social y a una buena administración. Si bien no hay un acuerdo unánime sobre el término, sí hay un consenso en que se mida con indicadores de impacto positivo en la formación de redes de confianza, buen gobierno, equidad y solidaridad.
} 
El Consejo, de acuerdo al Subprograma, tiene como misión: "lograr articular en un sistema nacional a las instituciones que atienden la educación y la capacitación de adultos que se apoye en las tecnologías modernas de información, aprendizaje y comunicación, además de otros recursos eficientes que cuente con los instrumentos para facilitar a todos el tránsito entre el mundo laboral y la educación formal y que reconozca los conocimientos, habilidades y destrezas adquiridas en uno y otro". Sin embargo, en éste y el siguiente párrafo, resalta su visión economicista, si bien el Consejo considera que el proceso educativo tiene como desafíos: la estructuración de modelos tanto pedagógicos como de gestión; hacer eficientes los aprendizajes; respetar potencialidades e identidades; y hacer de la tecnología factor de igualdad de oportunidades; es decir, responde en parte a la preocupación expresada en el contexto implícito, enfatizando lo laboral y olvidando la idea de ciudadanos responsables, solidarios y participativos.

En virtud de este enfoque - a nuestro juicio- limitado, creemos que es necesario plantear una propuesta sociopedagógica que recupere los principios rectores y los objetivos comunitarios $^{3}$ y que abarque, además de los organismos y dependencias oficiales previstos en el Subprograma, a los medios de difusión privados, para que en sus programas incluyan, reiteren y alienten los valores tradicionales que orienten hacia la construcción de una sociedad sana.

No debe olvidarse que el Subprograma de Educación para la Vida y el Trabajo también está dirigido a construir una cultura individual y colectiva. Por lo tanto, su papel no debe reducirse únicamente a impartir educación básica, sino que requiere el desarrollo de un sistema de redes que encauce la

${ }^{3}$ Podemos sintetizarlos como respeto a la autonomía en un mundo ordenado en el que se dé plena vigencia a la participación, representatividad y a la justicia social (Ver Etzioni, 1999). 
propia experiencia vital de quienes se retroalimentan con conocimientos en materias diversas (desde la Historia, la Literatura, el Arte, hasta la valoración de la Política y de las tradiciones y costumbres), raíz de nuestra cultura. Todo ello sin olvidar que es parte fundamental el fincar la dignidad humana y la responsabilidad social: una justa apreciación de los valores morales. Sin ella, es difícil que el societario se respete a sí mismo y que sepa, menos aún, respetar a los demás, a la sociedad, a su propio entorno.

La estrategia del CONEVYT consiste de echar mano de tres medios disponibles para el proceso educativo del adulto: presenciales, informáticos y televisivos. Hace mención de la biblioteca digital y puede enriquecer la educación presencial con material de Internet o viendo determinados programas de televisión. El Programa Nacional de Educación menciona, también, la conveniencia de operar descentralizadamente, "recibiendo propuestas locales".

Sin duda, la propuesta de utilizar la infraestructura existente y la idea de aprovechar todo lo existente en materia de educación continua es muy acertada. De ahí que sugerimos introducir y promover la educación continua para adultos que se realiza en la Universidad Panamericana, a través del Instituto de Cultura para Adultos Mayores. Si bien es cierto que el ámbito de acción del Instituto es el de los adultos mayores relacionados con la Universidad (abuelos, padres, familiares y amigos de los universitarios), las actividades podrían ser filmadas para canalizarlas, tanto a los diversos centros educativos de adultos, como al acervo de las videotecas de los mencionados centros de CONEVYT. 


\section{BIBLIGRAFÍA}

Etzioni, Amitai (1999). La Nueva Regla de Oro. España: Paidós. Pérez Adán, José (1999). La Salud Social. Madrid: Editorial Trotta. Secretaría de Educación Pública. (2001). Programa Nacional de Educación 2001-2006. México: SEP. 